\title{
Electrocardiographic Abnormalities in Hospitalized acute Cerebrovascular Events
}

\author{
ASMS MUNIR $^{\mathrm{a}}$, QT ISLAM ${ }^{\mathrm{b}}$, MR SIDDIQUI ${ }^{\mathrm{c}}$
}

\begin{abstract}
:
Background: - Physicians are confronted on having ECG in patients with acute stroke as it can mimic that of myocardial infarction or ischaemia. Repolarization and ischemic-like electrocardiographic (ECG) changes observed during acute phase of stroke may cause diagnostic and management dilemmas for the physicians.

Aim:- The aim and objective of this study to identify the prevalence of ECG changes in acute stroke patients admitted to medicine units of Dhaka Medical College Hospital.

Materials and Method: - This 6-month period observational study was carried out among 100 of acute stroke patients admitted in different medicine wards of Dhaka Medical College Hospital (DMCH). ECG was done in all patients after their admission to hospital within 48 hours of developing their symptoms. Association of various types of ECG changes were identified and observed.
\end{abstract}

Results: - Among 100 patients,55\% had ischaemic stroke and $45 \%$ had haemorrhagic stroke. $43.63 \%$ aged between 61-70 years had ischaemic stroke and $28.28 \%$ aged between 61-80 years had haemorrhagic stroke. Female had higher frequency of ischaemic stroke $52.72 \%$ and male had higher frequency of haemorrhagic stroke

Introduction:

Despite gradual declines in overall stroke death rates in many industrialized countries, stroke remains the third leading cause of death, with 160,000 strokerelated fatalities annually in the United States. Stroke

a. Dr. Abu Saleh Mohammed Sirajum Munir, Assistant Professor, Department of Medicine, Chandpur Medical College, Chandpur.

b. Prof. Quazi Tarikul Islam, Professor, Department of Medicine, Popular Medical College \& Hospital, Dhaka.

c. Dr. Mahmudur Rahman Siddiqui, Associate Professor, Department of Medicine, Anwer Khan Modern Medical College, Dhaka.

Address of correspondence:

Dr. Abu Saleh Mohammed Sirajum Munir, Assistant Professor, Department of Medicine, Chandpur Medical College, Chandpur.

Received: 11 May, 2020

Accepted: 13 July, 2020
75.56\%. Abnormal ECG found 84.44\% in haemorrhagic stroke and $54.54 \%$ in ischaemic stroke. Of all abnormal ECG, ST depression is most frequent and $42.22 \%$ in haemorrhagic stroke, $T$ inversion is next $20 \%$ in ischaemic stroke, $A F$ is present in $18.18 \%$ in ischaemic stroke and QT prolongation is found in $17.77 \%$ in hemorrhagic stroke. There considerable variation of ECG changes according to $C T$ scan evidence of particular area of brain involvement like ST depression (28.88\%) found in gangliothalamic bleed in haemorrhagic stroke, $A F$ is found (16.36\%) in insular area involvement in ischaemic stroke, $T$ inversion is more (12.72\%) in large MCA territory infarctive stroke and $Q T$ prolongation (11.11\%) is found in intracerebral haemorrhage including $\mathrm{SAH}$. Predictable early in hospital mortality is associated with AF $37.5 \%$ and with QT prolongation $31.25 \%$.

Conclusion:- In haemorrhagic stroke the ECG abnormalities were more frequent then in ischaemic stroke. The most common abnormalities were ST depression, $T$ wave inversion, $A F$ and $Q T$ prolongation. $A F$ and $Q T$ prolongation has association of early in hospital mortality.

Keywords:- Acute Stroke, ECG Changes.

(J Bangladesh Coll Phys Surg 2020; 38: 166-171)

DOI: https://doi.org/10.3329/jbcps.v38i4.48978

is also the leading cause of disability in adults. ${ }^{1}$ The annual incidence of acute cerebrovascular disease in the over 45 age group in the U.K. is about 180-300 per 100000. Cerebrovascular diseases can cause death \& disability by ischemia, from occlusion of blood vessel (producing cerebral ischemia \& infarction) or hemorrhage through their rupture. ${ }^{2}$ In India the prevalence rate of stroke was 250-350/ 100000 in last decade. ${ }^{3}$ In Bangladesh adequate and complete data on the incidence and mortality of stroke is not available. In one study in Dhaka Medical college Hospital, stroke is found to be the second commonest cause of emergency admission in the medicine ward and constituted about $10-12 \%$ of the total patient in this ward. Two studies in Chittagong Medical college Hospital and BIRDEM Hospital, Dhaka revealed 
respectively $2.58 \%$ and $5.8 \%$ of the admitted patients diagnosed as stroke. ${ }^{4}$

Given the disease burden of stroke, prevention is an important public health concern. Some of the modifiable risk factors like hypertension, diabetes mellitus, hyperlipidaemia, cigarette smoking and heart disease play vital role in the formation of the atherosclerotic plaque leading to thrombosis and embolism followed by ischemic stroke. Identification and control of modifiable risk factors is thus a good strategy to reduce the burden of stroke. ${ }^{5}$ Primary cardiac disorders can lead to stroke, but the idea that CNS disorder such as stroke may produce ECG changes and arrhythmia if fairly recent. For the first time in 1944, Byer and colleagues described the ECG changes in sufferers of subarachnoid hemorrhage. ${ }^{6}$ ECG changes are present in anywhere from $60-90 \%$ of patients with intra-parenchymal or subarachnoid bleed and in about $5-20 \%$ of patients with acute ischemic stroke. ${ }^{6}$ The underlying basis is disordered repolarization process. There is a relation between these changes and sudden death in sufferers of stroke. The possible mechanism is through disturbances in autonomic regulation and massive stimulation of the sympathetic nervous system. Moreover the studies have shown that the frontal lobe, insular cortex and amygdale play an important role in regulating the heart rate via autonomic nerves. ${ }^{6,7}$ ECG changes are not uncommon association in acute stroke patients. This study aims to identify different electrocardiographic changes after acute stroke patients, its frequency and its relation with particular type of stroke and any association of early in hospital mortality with particular ECG type.

\section{Materials and Methods:}

This observational cross sectional study was carried out among 100 randomly selected acute stroke indoor patients of Dhaka Medical College Hospital from Jan 2010 to June 2010. Patient admitted within 24 hours of onset of symptoms with confirm CT scan showing cerebral infarct or haemorrhage were included in this study. ECG was done in every patient on admission. A semi-structural questionnaire was followed by face to face interview on the basis of objective of the study. All interviewed questionnaire were checked for its completeness, accuracy and consistency to exclude missing or inconsistent data. Data were checked, cleaned and edited properly before analysis. Statistical analysis was carried out by using SPSS v16.0 Windows statistical software. All patients/ legal guardian were briefed about the study. Informed and written consent obtained from all patients who could give the consent and those who were unable to respond, their appropriate relatives/ legal guardian gave the consent. Confidentiality and privacy was maintained throughout the study.

\section{Result:}

Among 100 patients, maximum number of patients $(43.63 \%)$ in this study were in between $61-70$ years age group followed by $(32.72 \%)$ between $51-60$ years age group in ischaemic stroke. In haemorrhagic stroke maximum patients are between $61-70$ and $>70$ years age group $(28.88 \%, 28.88 \%$ respectively.) $55 \%$ had ischaemic stroke and $45 \%$ had haemorrhagic stroke. $43.63 \%$ aged between 61-70 years had ischaemic stroke and $28.28 \%$ aged between $61-80$ years had haemorrhagic stroke. Female had higher frequency of ischaemic stroke $52.72 \%$ and male had higher frequency of haemorrhagic stroke $75.56 \%$.

Abnormal ECG are found in $68 \%$ of stroke cases irrespective of their types.

Table 1: Distribution of the respondents by ECG abnormality $(n=100)$

\begin{tabular}{llll}
\hline ECG changes & Stroke Type & Total value
\end{tabular}

Ischaemic Stroke $(n=55) \quad$ Haemorrhagic Stroke $(n=45)$

\begin{tabular}{|c|c|c|c|c|}
\hline Abnormal & $30(54.54 \%)$ & $38(88.44 \%)$ & 68 & \\
\hline Normal & $25(45.45 \%)$ & $7(15.55 \%)$ & 32 & $0.001^{s}$ \\
\hline Total & 55 & 45 & 100 & \\
\hline
\end{tabular}

$n=$ Number of the patients 
This table shows that, abnormal ECG found in both hemorrhagic and ischaemic stroke and abnormality is slightly higher in hemorrhagic stroke $(84.44 \%)$ then in ischaemic stroke (54.54\%). And statistically significant difference $(0.001)$ was found between acute stroke (Ischaemic \& haemorrhagic) \& ECG changes.

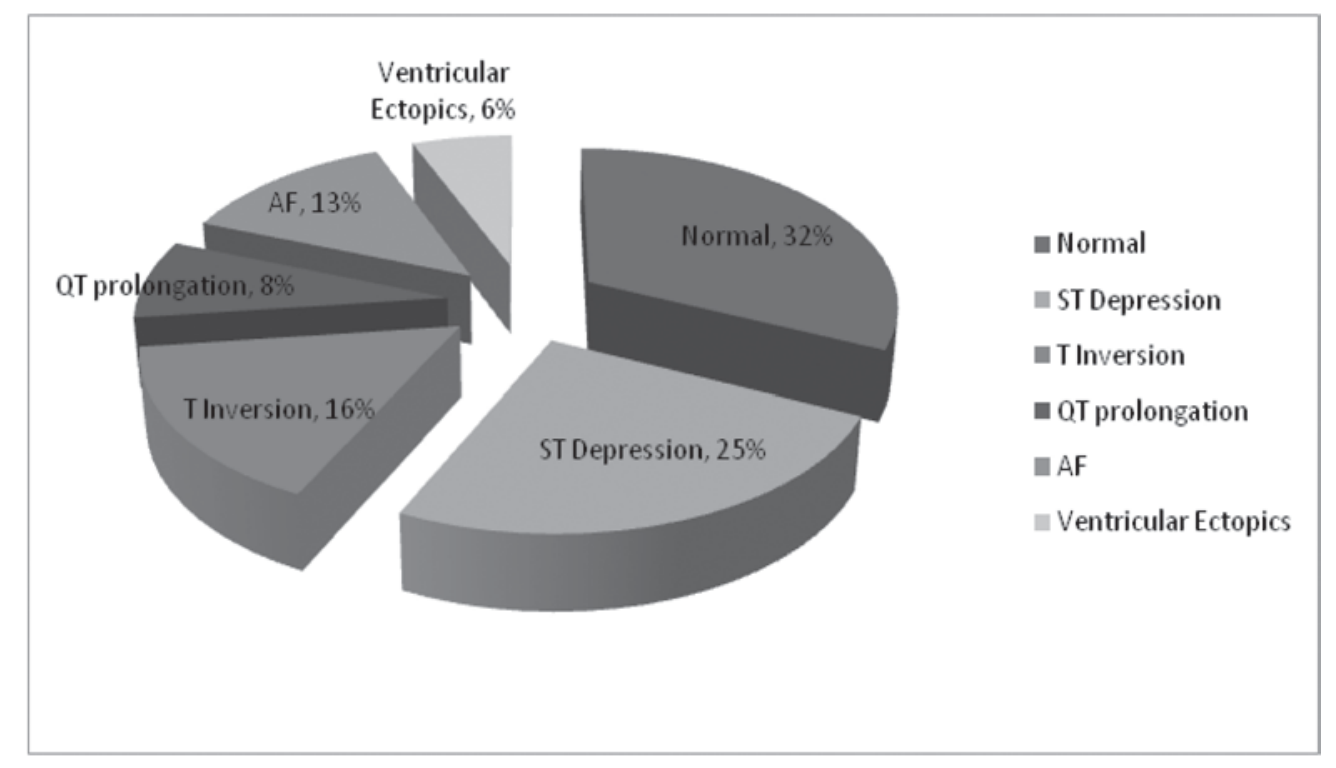

Fig 1: Frequency of normal and abnormal ECG in association with stroke.

This pie chart shows that, ST depression was most common ECG abnormality (25\%) then T inversion( $16 \%$ ). AF found at frequency of $13 \%$ and QT prolongation was $8 \%$ and ventricular ectopic was $6 \%$.

Table 2: Distribution of particular ECG abnormalities with type of stroke (n=100)

\begin{tabular}{|c|c|c|c|c|}
\hline \multirow[b]{2}{*}{$\begin{array}{l}\text { ECG } \\
\text { Changes }\end{array}$} & \multicolumn{3}{|c|}{ Type of Stroke } & \multirow[b]{2}{*}{ P-Value } \\
\hline & $\begin{array}{l}\text { Ischaemic Stroke } \\
\qquad(\mathrm{n}=55)\end{array}$ & $\begin{array}{l}\text { Haemorrhagic Stroke } \\
\qquad(\mathrm{n}=45)\end{array}$ & & \\
\hline Normal & $25(45.45 \%)$ & $7(15.55 \%)$ & 32 & $0.001^{\mathrm{S}}$ \\
\hline ST Depression & $6(10.90 \%)$ & $19(42.22 \%)$ & 25 & $0.05^{\mathrm{S}}$ \\
\hline $\mathrm{T}$ Inversion & $11(20 \%)$ & $5(11.11 \%)$ & 15 & $0.05^{\mathrm{S}}$ \\
\hline QT prolongation & $0(0 \%)$ & $8(17.77 \%)$ & 8 & $0.03^{\mathrm{S}}$ \\
\hline $\mathrm{AF}$ & $10(18.18 \%)$ & $3(6.66 \%)$ & 13 & $0.02^{\mathrm{S}}$ \\
\hline Ventricular ectopics & $3(0.01 \%)$ & $3(11.11 \%)$ & 6 & $0.10^{\text {ns }}$ \\
\hline Total & 55 & 45 & 100 & \\
\hline $\begin{array}{l}n=\text { Number of the } p \\
S=\text { Significant } \\
P \text { value reached fro }\end{array}$ & $\begin{array}{l}\text { ents } \\
\text { Chi square test. }\end{array}$ & & & \\
\hline
\end{tabular}


This table shows that here is significant statistical variation of normal and abnormal ECG between ischaemic and hemorrhagic stroke. Of all the abnormal ECGs, ST depression is the commonest and is found higher in hemorrhagic stroke $(42.22 \%)$ then in ischaemic stroke $(10.09 \%)$ and it is statically significant. Next is $\mathrm{T}$ wave inversion that is found more in ischaemic stroke $(20 \%)$ then in hemorrhagic stroke $(11.111 \%)$. AF that is found at higher frequency in ischaemic stroke $(18.18 \%)$ then in haemorrhagic stroke $(6.66 \%)$ and it is also statistically significant. QT prolongation is next that is found in haemorrhagic stroke $(17.77 \%)$ and the finding is also statistically significant. Ventricular ectopic beat found not significant is higher in hemorrhagic stroke.

Table 3: Distribution of particular ECG changes with involvement of particular site of brain evidence by CT Scan of brain $(n=100)$

ECG Changes Type of stroke

\begin{tabular}{lllllllll} 
& \multicolumn{3}{c}{ Ischaemic Stroke ( $=55)$} & \multicolumn{3}{c}{ Haemorrhagic Stroke ( n=45) } \\
& Lacunar & Insular & MCA territ & GanglThal & IC Hge & ICHgeVE & SAH \\
Normal & $9(16.36 \%)$ & $4(7.27 \%)$ & $12(21.81 \%)$ & $3(6.66 \%)$ & $2(4.44 \%)$ & $2(4.44 \%)$ & $0(0)$ \\
ST depression & $0(0)$ & $0(0)$ & $6(10.90 \%)$ & $13(28.88 \%)$ & $2(4.44 \%)$ & $3(6.66 \%)$ & $1(2.22 \%)$ \\
T inversion & $1(1.81 \%)$ & $2(3.63 \%)$ & $7(12.72 \%)$ & $3(6.66 \%)$ & $1(2.22 \%)$ & $2(4.44 \%)$ & $0(0)$ \\
QT prolongation & $0(0)$ & $0(0)$ & $0(0)$ & $0(0)$ & $0(0)$ & $5(11.11 \%)$ & $3(6.66 \%)$ \\
AF & $1(1.81 \%)$ & $9(16.36 \%)$ & $1(1.81 \%)$ & $0(0)$ & $0(0)$ & $2(4.44 \%)$ & $0(0)$ \\
Ventr. Ectopic & $0(0)$ & $1(1.81 \%)$ & $2(3.63 \%)$ & $2(4.44 \%)$ & $0(0)$ & $1(2.22 \%)$ & $0(0)$ \\
\hline Total (100) & $\mathbf{1 1}$ & $\mathbf{1 6}$ & $\mathbf{2 8}$ & $\mathbf{2 1}$ & $\mathbf{5}$ & $\mathbf{1 5}$ & $\mathbf{4}$
\end{tabular}

$\mathrm{n}=$ Number of the patients

Lacunar Stroke, Insular Stroke, MCA (Middle Cerebral Arterial) territory, GangThal (Gangliothalamic) stroke, IC(Intracerebral)

haemorrhage, ICHgeVE (Intracerebral Haemorrhage with ventricular extension.

This table shows that there is considerable variation of ECG changes according to area of involvement in CT Scan. ST depression is more at gangliothalamic bleed $(28.88 \%)$ then in large MCA territory ischaemic stroke $(10.90 \%)$. $\mathrm{T}$ inversion is more in ischaemic stroke and more found in large MCA territory infarctive stroke (12.72\%). QT prolongation almost exclusively occurs in hemorrhagic stroke and more in large intracerebral hematoma with ventricular extension (11.11\%) and in SAH (6.66\%). $\mathrm{AF}$ is more marked in ischaemic stroke and is found more in insular area involvement (16.36\%). Ventricular ectopic are found relatively less frequently and is more marked in gangliothalamic bleed then large MCA territory infarctive stroke.

\section{Discussion:}

A total of 100 patients with acute stroke $($ Ischemic $=55 \&$ Hemorrhagic $=45)$ were included in the study, during the study period, as per clinical criteria of acute stroke which were also CT scan proven. Among the study patients mean age was $61.04( \pm 10.32)$ in ischaemic stroke and 52.71( \pm 9.23$)$ in haemorrhagic stroke, this was consistent with the study conducted by Tarun, Rezaul ,Anwarullah, Anisul. ${ }^{[8]}$ In this study $72 \%$ were male and $28 \%$ were female i.e., male incidence is $30 \%$ higher than female which coincide with other international study. The present study coincides with the study of Chowdhury et al, ${ }^{[9]}$ and Kurtzke, ${ }^{[10]}$ where showed that frequency of stroke is $30 \%$ higher in men than women. In this series abnormal ECG found in both hemorrhagic and ischaemic stroke and abnormality is slightly higher in hemorrhagic stroke $(84.44 \%)$ then in ischamic stroke (54.54\%). Khechinashvili G, Asplund K et al showed this similar result in their study where prevalence of ECG changes were higher in haemorrhagic stroke. ${ }^{[11,12]}$ 
Of all the abnormal ECGs, ST depression is the commonest and is found higher in hemorrhagic stroke (42.22\%) then in ischaemic stroke (10.09\%) and it is statically significant. This is consistent with study done by Byer E, Ashman R, Toth LA et al. ${ }^{[13]}$. Next is $\mathrm{T}$ wave inversion that is found more in ischaemic stroke (20\%) then in hemorrhagic stroke (11.111\%) Burch GE, Meyers R, Abildskov JA showed smiliar result in their study. ${ }^{[14]}$ Levine HD and Kreus KE, Kemilä SJ, Takala JK et al showed in their study that $\mathrm{T}$ wave inversion was more marked in acute ischaemic stroke. ${ }^{[15][16]}$. AF that is found at higher frequency in ischaemic stroke $(18.18 \%)$ then in haemorrhagic stroke $(6.66 \%)$ and it is also statistically significant and similar result observed by Burch GE, Meyers R, Abildskov JA et al. ${ }^{[14]}$ QT prolongation is next that is found in haemorrhagic stroke $(17.77 \%)$ and the finding is also statistically significant. Levine HD and Dimant J, Grob D showed in their study that QT prolongation was more in haemorrhagic stroke. ${ }^{[15,17]}$

There is considerable variation of ECG changes according to area of involvement in CT Scan of Brain. ${ }^{[18]}$ ST depression is more at gangliothalamic bleed $(28.88 \%)$ then in large MCA territory ischaemic stroke $(10.90 \%)$ S. Oppenheimer showed similar result in his study. $\mathrm{T}$ inversion is more in ischaemic stroke and more found in large MCA territory ischaemic stroke $(12.72 \%)$ this is consistent with study done by $\mathrm{H}$ Christensen, G Boysen, A F Christensen, et al ${ }^{[18]}$. QT prolongation almost exclusively occur in hemorrhagic stroke and more in large intracerebral hematoma with ventricular extension (11.11\%) and in SAH (6.66\%) and Nazire, Ali S.Fak, Jacques T. Metzger, Guy Van Melle et al, showed that SAH has about $85 \%$ association of QT prolongation. ${ }^{[19]} \mathrm{AF}$ is more marked in ischaemic stroke and is found more in insular area involvement $(16.36 \%)$. Ventricular ectopics are found relatively less frequently and is more marked in gangliothalamic bleed then large MCA territory stroke. ${ }^{[19,20,21]}$. The results found on this study coincided with other study as mentioned .

\section{Conclusion:}

In our country, there are many studies on stroke, its associated conditions and their effect on stroke patient's outcome, but no study done previously about the ECG changes which is a one of the interesting concern of many countries. In this study, I attempted to find out the common ECG abnormalities in acute stroke patients. The results of this study demonstrates that, in haemorrhagic stroke, the incidence of ECG changes were more than ischaemic stroke and which were mostly ST depression and QT prolongation .It was also observed that in ischaemic stroke the common changes were $\mathrm{T}$ inversion and $\mathrm{AF}$. There is considerable variation of ECG changes according to area of involvement in CTS. ST depression is more at gangliothalamic bleed then in large MCA territory ischaemic stroke. T inversion is more in ischaemic stroke and more found in large MCA territory ischaemic stroke. QT prolongation almost exclusively occur in hemorrhagic stroke and more in large intracerebral hematoma with ventricular extension and in $\mathrm{SAH} . \mathrm{AF}$ is more marked in ischaemic stroke and is found more in insular area involvement.

Conflict of interest: We have no conflict of interest.

\section{References:}

1. Jose Biller and Betsy B. Love. ' Vascular Diseases of the Nervous System. ISCHEMIC CEREBROVASCULAR DISEASE.' In Walter G.Bradly, Robert B Daroff, Gerald M Fenichel, Joshep Jankovic, Neurology in Clinical Practice. Principle of diagnosis and Management. 4th edn, Elsevier; 2006 ;Chapter 57 : 1197.

2. Allen CMC, Lueck CJ, Dennis M. Neurological disease. In : Boon NA, Colldge NR, Walker BR, Hunter JAA, editors. Davidson's Principles and Practice of Medicine. 20Th ed. London : Churchill Livingstone Elsvier; 2006. p. 1200-10.

3. Banejee TK\& Das SK ,'Epidemiology of stroke in India', Neurology Asia, 2006;11,1-4.

4. Latif ZA, Zaman SM, Barua A et al. 'Study of stroke between normotensive and hypertensive NIDDM case in BIRDEM, Dhaka. Bangladesh Journal of Neuroscience 1990;6:52-59.

5. Smith WS, JHohnston SC, Easton JD. Cerebrovascular diseases. IN: kasper DL, Braunwald E, Fauci AS, Hauser SL, Longo DL, Jameson JL, editors. Harrison's Principles of Internal Medicine. 16th ed. Vol. 2. New Delhi; McGraw-Hill; 2005. p. 2372-93.

6. George Khechinashvili, Kjell Asplund "Electrocardiographic Changes in Patients with Acute Stroke: A Systematic Review." S. Karger AG, Basel; Cerebrovasc Dis 2002;14:67-76

https://doi.org/10.1159/000064733.PMid:12187009

7. S Grmec, D Kupnik, M Strnad and M Spindler. "Electrocardiographic changes in patients with acute stroke in the pre hospital setting and their prognostic importance." Critical Care 2006;10(1):457. https://doi.org/10.1186/cc4804.PMCid:PMC4092832 
8. Tarun KS, Ruhul K, Rezaul KK, Anwarullah AKM, Rafiqul I, Anisul $\mathrm{H}$ et al. "Dyslipidaemia in Cortical Versus Subcortical Infarction". Bangladesh Journal of Neuroscience 2008; Vol. 24 (1) : 24-33. https://doi.org/10.3329/bjn.v24i1.3037

9. Chowdhury SZM. Study of risk factor in cerebrovascular disease- A study of 100 cases (Dissertation). BCPS 1991:48.

10. Kurzke JF. Epidemiology of cerebrovascular disease. In :P.Rowland L, editor. Merrtt's Neurology. Philadelphia: LLW;2000:135-76.

11. Electrocardiographic Changes in Patients with Acute Stroke: A Systematic Review George Khechinashvili, Kjell Asplund Department of Medicine, University Hospital, Umea, Sweden Cerebrovasc Dis 2002;14:67-76. https://doi.org/10.1159/000064733 PMid:12187009

12. Khechinashvili G, Asplund K. Electrocardiographic changes in patients with acute stroke:A systematic review. Cerebrovasc Dis 2002;14:67-76. https://doi.org/10.1159/000064733.PMid:12187009

13. Byer E, Ashman R, Toth LA. Electrocardiograms with large, upright $\mathrm{T}$ waves and long Q-T intervals. Am Heart J 1947;33:796-806. https://doi.org/10.1016/0002-8703(47)90025-2

14. Burch GE, Meyers R, Abildskov JA. A new Electrocadiographic pattern observed in cerebrovasular accidents. Circulation 1954;9:719-23. https://doi.org/10.1161/01.CIR.9.5.719. PMid:13161103
15. Levine HD. Non-specificity of the electrocardiogram associated with coronary heart disease. Am J Med 1953;15:344-55. https://doi.org/10.1016/0002-9343(53)90088-6

16. Kreus KE, Kemilä SJ, Takala JK. Electrocardiographic changes in Cerebrovascular accidents. Acta Med Scand 1969;185:327-34. https://doi.org/10.1111/j.0954-6820.1969.tb07342.x. PMid:5806339

17. Dimant J, Grob D. Electrocardiographic changes and myocardial damage in patients with acute Cerebrovascular accidents. Stroke 1977;8:448-55. https://doi.org/10.1161/01.STR.8.4.448.PMid:898240

18. Insular lesions, ECG abnormalities, and outcome in acute stroke $\mathrm{H}$ Christensen, $\mathrm{G}$ Boysen, A F Christensen, et al.2005 76: 269-271 J Neurol Neurosurg Psychiatry.https://doi.org/10.1136/jnnp.2004.037531. PMid:15654050; PMCid:PMC1739524

19. Neurothanatology-clinical significance of cerebrally induced cardiac changes. S. Oppenheimer, Postgrad Med J 1990 66: 591-594, doi: 10.1136/pgmj.66.778.591. https://doi.org/10.1136/pgmj.66.778.591.PMid:22170 27; PMCid:PMC2429673

20. Bell DA, Brien W, Vladimar $H$ et al. Antiphospholipid synd: prevalence among patients with stroke and TIA. Am J Med 1990;88:593-97. https://doi.org/10.1016/0002-9343(90)90523-G 